E3S Web of Conferences 1, 27002 (2013)

DOI: $10.1051 / \mathrm{e} 3$ sconf/20130127002

(C) Owned by the authors, published by EDP Sciences, 2013

\title{
Influence of emissions on regional atmospheric mercury concentrations
}

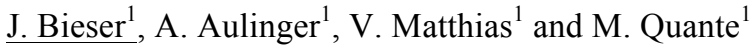 \\ ${ }^{1}$ Department for Environmental Chemistry, Institute of Coastal Research, Helmholtz-Zentrum Geestacht, 21502 \\ Geesthacht, Germany,johannes.bieser@hzg.de
}

\begin{abstract}
Mercury is a global pollutant that is rapidly transported in the atmosphere. Unlike the majority of air pollutants the background concentrations of mercury play a major role for the atmospheric concentrations on a hemispheric scale. In this study the influence of regional anthropogenic emissions in comparison to the global emissions on mercury concentrations over Europe are investigated. For this purpose an advanced threedimensional model system is used that consists of three components. The emission model SMOKE-EU, the meteorological model COSMO-CLM, and the chemistry transport model (CTM) CMAQ. A variety of sensitivity runs is performed in order to determine the influence of different driving factors (i.e. boundary conditions, anthropogenic and natural emissions, emission factors, meteorological fields) on the atmoshperic concentrations of different mercury species. This study is part of the European FP7 project GMOS (Global Mercury Observation System). The aim is to identify the most important drivers for atmospheric mercury in order to optimize future regional modelling studies in the course of the GMOS project. Moreover, the model results are used to determine areas of interest for air-plane based in-situ measurements which are also part of GMOS.
\end{abstract}

Key words: mercury, atmospheric concentration, chemistry transport modelling, natural emissions

\section{Introduction}

Mercury in its various chemical states is known to have adverse effects on human health. The European Union FP7 Research Project GMOS (Global Mercury Observation System) is currently working on the implementation of a world spanning observation system for atmospheric mercury. GMOS also includes global and regional modelling of atmospheric mercury. Here, the focus is on the possible improvement of the mercury chemistry schemes, on the coupling of the global and regional model systems and their application to investigate past and future pathways of atmospheric mercury transport. Three different model systems are used on the regional scale, one of it is the Hg-version of the Community Multiscale Air Quality (CMAQ) model (Byun and Schere, 2006). At the Helmholtz-Zentrum Geesthacht, CMAQ-Hg is

applied to determine atmospheric concentrations of mercury over Europe.

This study concentrates on the influence of anthropogenic emissions on atmoshperic mercury concentrations on regional scales. Because of the high background concentrations of mercury in the northern hemisphere (about 1 to $2 \mathrm{ng} / \mathrm{m}^{3}$ ) and the importance of re-emissions (roughly half of the global mercury emissions are due to re-emissions from different environmental compartments) the influence of single anthropogenic sources on the global atmospheric mercury concentration is small. On a regional scale, how ever, large point sources can have a strong impact on atmospheric mercury concentrations.

This work is also closely related to the air- plane based in-situ measurements to be performed in the course of the GMOS project. The aim of the measurement campaigns is to obtain more detailled information about the vertical distribution of mercury as well as the detection of mercury plumes from specific source regions to investigate the variability of atmospheric mercury concentrations. The regional model results are used to identify representative regions for these measurement campaigns.

\section{Materials and Methods}

To study the influence of mercury emissions on atmoshperic concentrations an advanced three dimensional model system is used which consists of three components. An emission model, a meteorological model and a chemistry transport model (CTM). The CTM used is a version of CMAQ which includes a mercury chemistry scheme (Byun and Schere, 2006). The CMAQ model includes a full representation of ozone chemistry and particle physics for three particle size classses. For VOC chemistry the carbon bond 5 (cb05) chemical mechanism is used (Yaarwood et al., 2005). 
CMAQ-Hg additionally includes three different mercury species: elemental mercury $\left(\mathrm{Hg}^{0}\right)$, gaseous oxidized mercury $(\mathrm{GOM})$, and particulate mercury $\left(\mathrm{Hg}_{\mathrm{P}}\right)$ (Bullock and Brehme, 2002). Meteorological fields are taken from the models COSMO-CLM (Rockel et al., 2008) and WRF (Skamarock and Klemp, 2007). Hourly gridded emissions of precursors of criteria pollutants and aerosols are created with the SMOKE for Europe emission model based on annual emission estimates from EMEP and EPER (Bieser et al., 2011). Moreover, annual anthropogenic mercury emissions from a global emission inventory for 2005 (Pacyna et al., 2010) are distributed in space and time by SMOKE for Europe. Re-emissions of mercury will be estimated using the methodology of Bash (2009) who developed a CMAQ module that parametrizes the concentration dependent bi-directinal flux of mercury between the atmosphere and vegetation, soil, and water bodies.

CMAQ is run with a horizontal grid resolution of $72 \times 72 \mathrm{~km}^{2}$ including a nested grid with $24 \times 24 \mathrm{~km}^{2}$ resolution. Additionally source regions of special interest (e.g. the Rhine-Ruhr area) will be modeled with a resolution of $6 \times 6 \mathrm{~km}^{2}$. In the vertical dimension 30 layers up to a pressure altitude of $50 \mathrm{hPa}$ are used. The model domain is depicted in figure 1. Boundary conditions are taken from two different global models ECHMERIT (Jung et al., 2009) and GLEMOS (Travnikov and Ilyin, 2009). To identify the influence of the different parameters on mercury concentrations CMAQ is run with different combinations of input data for the year 2009 .

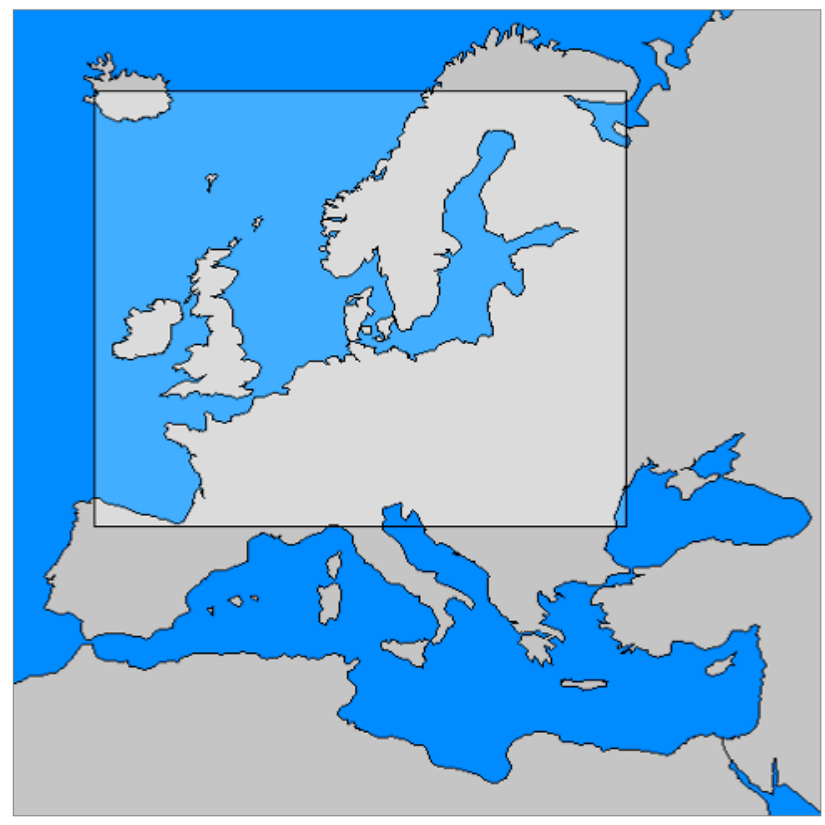

Fig. 1. The regional model domain $\left(72 \times 72 \mathrm{~km}^{2}\right)$ and the nested domain $\left(24 \times 24 \mathrm{~km}^{2}\right)$ covering the entire Northand Baltic Sea. catchment areas.

\section{Results and Discussion}

The most common meteorological condition over Europe are westerly to north-westerly winds. This means that when modelling atmospheric pollutants over Europe the boundary conditions mostly transport clean, unpolluted air into the regional model domain. This is true for most atmospheric polutants (e.g. criteria pollutants and most POPs). For mercury, however, the boundary conditions are crucial since large amounts of mercury are transported into the model domain. This is due to the fact that deposited mercury is steadily re-emitted as $\mathrm{Hg}^{0}$ from the ocean and soils. Especially the Atlantic ocean is a net source for mercury (Soerenson et al, 2010).

Because of this it is important to make sure that the global models that yield the boundary conditions for the regional model use a chemical mechanism and emission factors comparable to those used by the regional model. Furthermore, the interpolation of the global model needs to be done accurately. In practice the interpolation of the vertical layers is often problematic due to different topologies, which are dependent on the spatial resolution, and different definitions of layer height.

A comparison of model runs with and without anthropogenic emissions was performed to quantify the influence of these emissions on atmospheric concentrations. The majority $(60 \%)$ of the European mercury emissions are in form of elemental mercury. However, the concentrations of $\mathrm{Hg}^{0}$ over Europe were determined predominantly by the boundary conditions. The signal of anthropogenic emissions could only be detected for oxidized mercury $\left(\mathrm{Hg}^{2+}=\sum \mathrm{GOM}+\mathrm{Hg}_{\mathrm{P}}\right)$. In rural regions in central Europe $2 \%$ to $5 \%$ of the total mercury was oxidized, in urban regions the ratio was in the range of $6 \%$ to $12 \%$ (Fig. 2). These values are in the range of observations ( $1 \%$ to $13 \%$ ) performed by HZG at the German measurement station Waldhof using a full speciation Tekran instrument (Liu et al., 2007).

Since only elemental mercury and total mercury can be measured with a temporal resolution small enough to be used for air-plane based measurements this ratio is important to determine areas of interest for measurement campaigns. Two particular routes for air-plane based measurements have been identified: a flight mission over the Rhine-Ruhr area which has a much higher $\mathrm{Hg}^{2+} / \mathrm{Hg}_{\text {тот }}$ ratio than the surrounding rural area and a flight from the Po- valley to Mount Etna because it is a large point source for mercury.

\section{Conclusion and Outlook}

Because of the large influence of background concentrations it is necessary to investigate the ratio of different mercury species to identify the influence of different anthropogenic and natural (e.g. volcanic activity) sources. Depending on source type up to $60 \%$ of the emissions can be in the form of $\mathrm{Hg}^{2+}$ while in the global background concentrations only about $2 \%$ of the mercury is in an oxidized form. Thus, regional sources that have a negligible influence on the total atmospheric mercury burden can be identified by changes in the $\mathrm{Hg}^{2+} / \mathrm{Hg}_{\text {TOT }}$ ratio. In rural regions this ratio is of the order of $1 \%$ to $5 \%$ while in the proximity of a source it can be $20 \%$ or higher.

The study presented here is a work in progress and thus several model runs and analysis have not yet been completed. It is planned to investigate the influence of the model resolution on the visibility of regional emission sources. For this purpose the CMAQ model will be run on a higher spatial resolution of $6 \times 6 \mathrm{~km}^{2}$ over source regions in central Europe. The first air-plane 
a)

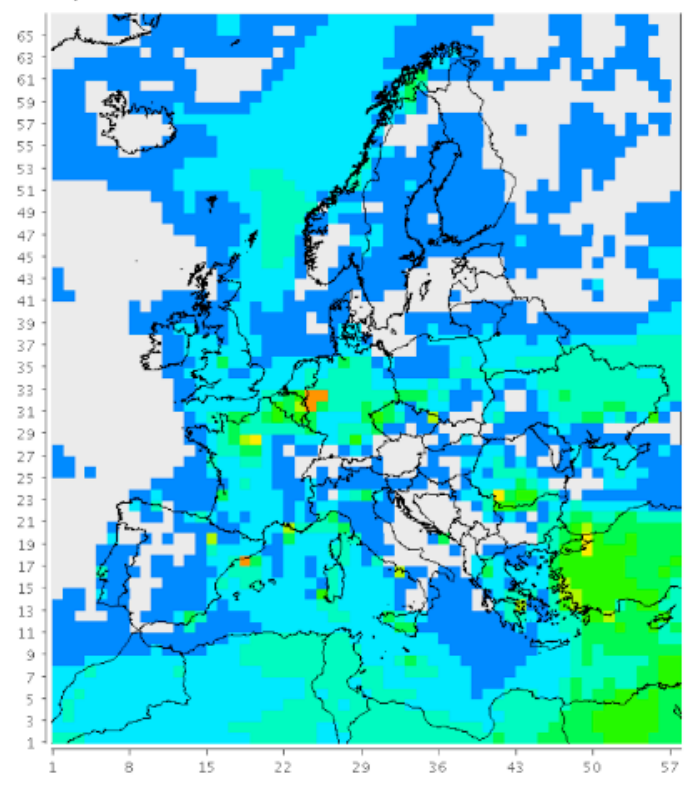

b)

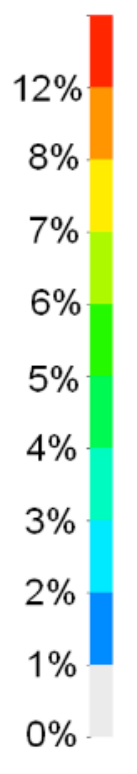

b)

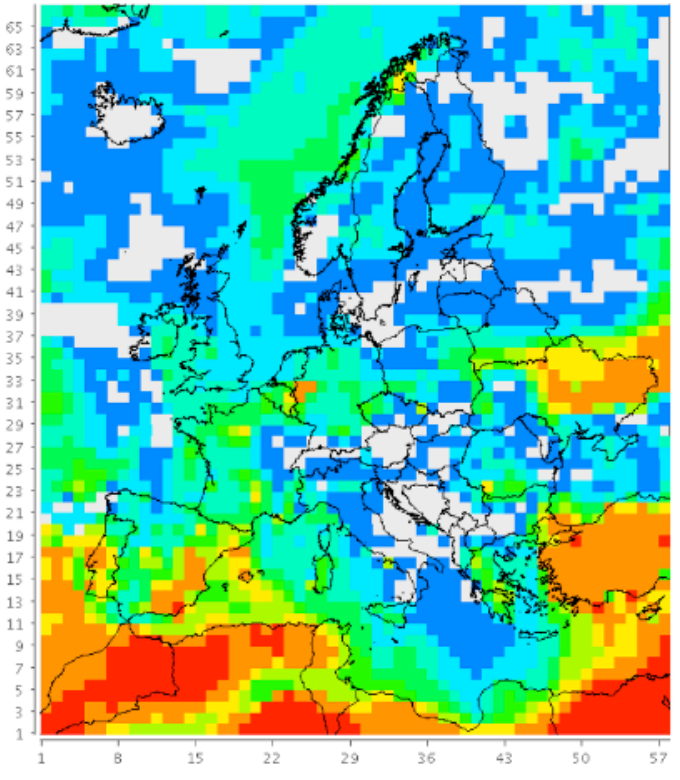

$12 \%$

$8 \%$

$7 \%$

$6 \%$

$5 \%$

$4 \%$

$3 \%$

$2 \%$

$1 \%$

$0 \%$

Fig. 2. Ratio of oxidized mercury $\left(\mathrm{Hg}^{2+}=\sum \mathrm{GOM}+\mathrm{Hg}_{\mathrm{P}}\right)$ to total mercury $\left(\mathrm{Hg}_{\mathrm{TOT}}=\sum \mathrm{Hg}^{0}+\mathrm{Hg}^{2+}\right)$ in an altitude of $250 \mathrm{~m}$ to $400 \mathrm{~m}$ in July 2009 using boundary conditions from different global models a) GLEMOS, b) ECHMERIT. (preliminary results)

based in-situ measurements in the course of the GMOS project are scheduled for July and August 2012. Observed concentrations of elemental mercury $\mathrm{Hg}^{0}$, total gaseous mercury (TGM) and other selected species (e.g. $\mathrm{CO})$ will be compared to model results from the high resolution CMAQ runs. To further investigate the influence of the boundary conditions on regional atmospheric mercury concentrations data from alternative global chemistry transport models will be used. Moreover it is planned to perform a hemispheric CMAQ run in order to create boundary conditions which are based exactly on the same methodology as the regional simulation.

\section{Acknowledgements}

The authors thank for the financial support from the Eropean Union (FP7 Project GMOS) and the US EPA for providing the CMAS model system.

\section{References}

Bash, J.O., 2010. Description and initial simulation of a dynamic bidirectional air-surface exchange model for mercury in Community Multiscale Air Quality (CMAQ) model. Journal of Geophysical Research, 115, D06305, 15 pp. doi:10.1029/2009JD012834.

Bieser, J., Aulinger, A., Matthias, V., Quante, M., Builtjes, P., 2011. SMOKE for Europe - adaptation, modification and evaluation of a comprehensive emission model for Europe. Geosci. Model Dev. 4, 1-22, doi:10.5194/gmd-4-1-2011.

Bullock, O.R., Jr. and Brehme, K.A., 2002. Atmospheric mercury simulation using the CMAQ model: formulation description and analysis of wet deposition results. Atmos. Environ. 36, 2135-2146.
Byun, D.W. and Schere, K.L., 2006. Review of the governing equations, computational algorithms, and other components of the Models-3 community Multiscale Air Quality (CMAQ) modeling system, Appl. Mech. Rev., 59(2), 51-77.

Jung, G., Hedgeckock, I.M., Pirrone, N., 2009. ECHMERIT V1.0 - a new global fully coupled mercury- chemistry and transport model. Geosci. Model Dev. 2, 175-195.

Liu, B., Keeler, G.J., Dvonch, J. T., Barres, J.A.,Lynam, M. M., Marsik, F. J., Morgan, J. T., 2007. Temporal variability of mercury speciation in urban air. Atmos. Environ. 41, 9, 1911-1923.

Pacyna, E., Pacyna, J., Sundseth, K., Munthe, J., Kindbom, K., Wilson, S., Steenhuisen, F., Maxson, P., 2010. Global emission of mecury to the atmosphere from anthropogenic sources in 2005 and projections to 2020. Atmos. Environ. 4, 2487-2499.

Rockel, B., Will, A., and Hense, A., 2008. The Regional Climate Model COSMO-CLM (CCLM), Meteorol. Z., 17, 347-248, 2008.

Skamarock ,W.C., Klemp, J.B., 2007. A Time-Split Nonhydrostatic Atmospheric Model for Weather Research and Forecasting Applications. J. Comp. Phys., spec. issue environmental modeling 34653485.

Travnikov O. and Ilyin I. (2009) The EMEP/MSC-E mercury modeling system. In: Pirrone N., Mason R. (Eds.) Mercury fate and transport in the global atmosphere. Springer, 571-587.

Yarwood, G., Rao, S., Yocke, M., Whitten, G.Z., 2005. Updates to the Carbon Bond Mechanism: CB05. US EPA Final Report, 161 pp. 